\title{
Analytical Method for the Determination of Surfactants with Fluorescent Activity, Present in Liquid Effluents from Textile Industries, by HPLC- Fluorescence
}

\author{
Martínez Ramón Alberto ${ }^{1 *}$, Fechner Diana Corina ${ }^{1}$, Ruiz Díaz Juan Daniel ${ }^{1}$ \\ and Vazquez Francisco Antonio ${ }^{1}$ \\ ${ }^{1}$ Laboratorio de Química Ambiental, Facultad de Ciencias Exactas y Naturales y Agrimensura, \\ Universidad Nacional del Nordeste, Av. Libertad 5470 - Corrientes, Argentina.
}

\begin{abstract}
Authors' contributions
This work was carried out in collaboration between all authors. The authors MRA and FDC made the field task, performed the laboratory assays and the statistical analysis, and wrote the first draft of the manuscript. The author RDJD performed laboratory assays. The author VFA managed the analyses of the study and the literature searches, revised and corrected the manuscript. All authors read and approved the final manuscript.
\end{abstract}

Article Information

DOI: $10.9734 / I R J P A C / 2017 / 36636$ Editor(s):

(1) Bengi Uslu, Department Analytical Chemistry, Ankara University, Ankara, Turkey. Reviewers:

(1) Vladimíra Tomečková, University of Pavol Jozef Šafárik in Košice, Slovakia. (2) Diène Diégane Thhiare, Cheikh Anta Diop Universitty, Senegal. (3) Elzbieta Regulska, University of Bialystok, Poland. Complete Peer review History: http://www.sciencedomain.org/review-history/21205

Original Research Article

Received $5^{\text {th }}$ September 2017 Accepted $26^{\text {th }}$ September 2017 Published $2^{\text {nd }}$ October 2017

\begin{abstract}
In textile industries effluents we can be found surfactants of various characteristics, alkalis, and sulfides partially or totally hydrolyzed dyes, among other things, which are used as dyeing material. This study aims to create an unconventional tool to evaluate the degree of environmental contamination as a consequence of the discharge of these compounds that constitute the effluents of the textile industry prior to its final disposal, with or without purification systems, following one or more of its constituents possessing fluorescent properties.

It was designed a technique to determine and quantify surfactant compounds used in textile industry. The conditions of the technique by HPLC with fluorescence detector designed are: Mobile
\end{abstract}


phase: $\mathrm{H}_{3} \mathrm{CCN} / \mathrm{NaClO}_{4}(12.3 \mathrm{~g} / \mathrm{L})$ 65:35; flow: $1 \mathrm{~mL} / \mathrm{min}$; column: Waters Symmetry C18 $5 \mu \mathrm{m} ; 4.6 \mathrm{x}$

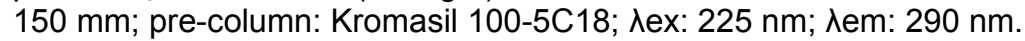

It was found that the commercial textile surfactants analyzed have matching constituents, but also have some unique characteristics that identify and discriminate. Surfactants Tensia MA, Unipal DLE and Croscolor Miro have their own fluorescent compounds, which will be used as contamination indicators to monitor or evaluate the environmental impact of textile effluents on water bodies receiving.

Keywords: Effluent; oxidation; remediation; textile.

\section{INTRODUCTION}

The effluents of textile industries cause severe environmental problems due to the high content of toxic and corrosive chemicals in large volumes of water as a result of the different processes that it carries out. The consequent is generation of effluents of very diverse composition and hazard to superficial water receiver $[1,2]$. They are constituted by a great diversity of compounds including surfactants, in which the ones of character "no ionics" and "anionics" are distinguish. The two most commonly used types at all wet processes are Alkylphenol ethoxylates (APEO) and ethoxylated alcohols (AE), and to a lesser extent the use of Linear Alkylbenzenesulfonates (LAS), which have an anionic character. These surfactants are used both in washing processes and in dyeing processes as levelers in the absorption of the dye on the fiber, emulsifiers and in the textile finishing [3].

The determination of surfactants has been extensively studied. It has been used different analytical methodologies such as color test, molecular adsorption spectrophotometry, liquid chromatography (HPLC) [4,5]. Also it has been used the simple and rapid spectrophotometric method for the determination of any anionic surfactant, associated with a cationic dye proposed by Kamaya et al. [6].

The limit of detection of the surfactants in HPLCUV for direct injection is very high which makes it no accessible for direct determinations in environmental samples according to Hong \& Slingsby [7]. Castles et al. [8] have presented a modification to liquid chromatography, improving the cleanup stage and stimulating the preconcentration for the detection of LAS in environmental samples. And recently, Motteran et al. [9] have been present a new method for determination of LAS and nonionic surfactant in commercial laundry wastewater, using LCMS/MS.
The aim of this work is to develop an affordable method of detection and quantification of surfactant compounds with fluorescent activity employed in textile industries, to establish a contamination/purification indicator mechanism to be used in textile effluents and in the water bodies receiving the overturn.

The verification of the presence of compounds LAS, APEO and AE could be used as indicator of the environmental impact of effluents from textile industries with or without treatment systems and the degree of alteration caused to the water bodies receiving. The importance of this work lies in the creation of a tool to decide on contamination of water resources by anthropic activity in particular by activity of textile industries by checking the existence and monitoring of nonconventional pollution indicators such as residues of surfactant compounds with fluorescent activity or some of their degraded components which retain those properties.

\section{EXPERIMENTAL DETAILS}

\subsection{Equipment}

Waters Breeze HPLC, with column oven and fluorescence detector model 2475.

Symmetry C18 $5 \mu \mathrm{m}$ column, 4.6 x $150 \mathrm{~mm}$.

Pre-column Kromasil 100-5C18, $50 \mathrm{~mm}$.

Gamafil MGF-NYL022-SC nylon syringe filter $0.22 \mu \mathrm{m}$.

\subsection{Reagents}

Water Grade HPLC Sintorgan.

Acetonitrile grade HPLC Sintorgan,

Sodium perchlorate $\left(\mathrm{NaClO}_{4} \cdot \mathrm{H}_{2} \mathrm{O}\right)$, Analar, $\mathrm{BDH}$ Chemicals Ltd Poole England. 
The selection of the surfactants to be tested was performed based on those that are used mainly in the different textile processes. Thus, it was selected commercial products frequently used by textile industries of Argentina now a day. The surfactants tested were as follows, for the next citations will be referred generically as identify between parentheses:

Tensia MA (Surfactant 1): humectant-detergent with anionic character.

Eriopon OS (Surfactant 2): humectantdetergent, with no ionic character, composition of fatty acid derivatives.

Unipal DLE (Surfactant 3): detergenthumectant free of phenols, anionic character.

Croscolor Miro (Surfactant 4): detergenthumectant-emulsifier, of weakly anionic nonionic character.

The molecular structures of general anionic and noionic sufactants employed in the present work are show in Fig. 1.

\subsection{Method}

\subsubsection{Selection of the mobile phase}

The mobile phase chosen for preliminary tests was $0.05 \mathrm{M} \mathrm{NaClO}_{4}$ in $\mathrm{HPLC}$ grade water, taking into account the work published Reemtsma [10]. The signals obtained were not satisfactory for the detection and quantification requirements, so the mobile phase was modified by choosing $\mathrm{H}_{3} \mathrm{CCCN} / \mathrm{NaClO}_{4} \quad 65 / 35$ (v/v) as used by Hirayama et al. [11]. This mobile phase was adequate for the quantification of standards (commercial surfactants), so it was adopted as a routine mobile phase.

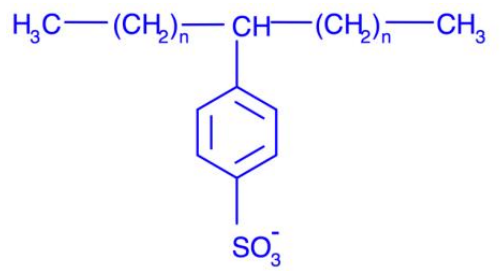

\subsubsection{Mobile phase flow}

Once the mobile phase was selected, different flows rates were tested starting from $0.6 \mathrm{~mL} / \mathrm{min}$, increasing until obtaining the optimum in 1 $\mathrm{mL} / \mathrm{min}$. Higher fluxes produced separation deficits and less than $0.6 \mathrm{~mL} / \mathrm{min}$ were inconvenient because of increase in the analysis times.

\subsubsection{Determination of excitation and emission wavelengths}

Optimum excitation and emission wavelengths were tested for the detection and quantification of fluorescent components in standards. Thus, an excitation sweep was initially performed between the wavelengths 210 and $250 \mathrm{~nm}$ for each standard. To do this, the emission wavelength ( $\lambda$ em) was fixed at $297 \mathrm{~nm}$, according to the literature consulted $[5,12]$. The determination for each of the standards was done in triplicate.

Graphics provided by HPLC-Waters software, Empower, are in 2D and 3D. 2D graphs are presented in Fig. 2 because they are easy to interpret. The optimal excitation wavelengths ( $\lambda$ ex) found for the investigated components are observed. The four surfactants analyzed have the maximum excitation between 215 and 235 $\mathrm{nm}$, the centroid of the 2D graphs being obtained at $225 \mathrm{~nm}$, so this wavelength was selected as the optimum.

For the scanning of the emission wavelengths, it was work with the previously selected excitation wavelength: $225 \mathrm{~nm}$. Surfactants 1, 2 and 3 showed maxima for the emission lengths between 295 and $300 \mathrm{~nm}$. Surfactant 4 showed the maximum between 285 and $295 \mathrm{~nm}$. Therefore, in compromise, the emission wavelength is chosen at $297 \mathrm{~nm}$, to study them together.

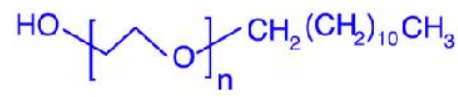

Fig. 1. Left: Molecular structure of the anionic surfactant linear alkylbenzene sulfonate (LAS), $n=7$ to 11. Right: Molecular structure of the noionic surfactant linear alcohol ethoxylate (LAE), $n>10$ 


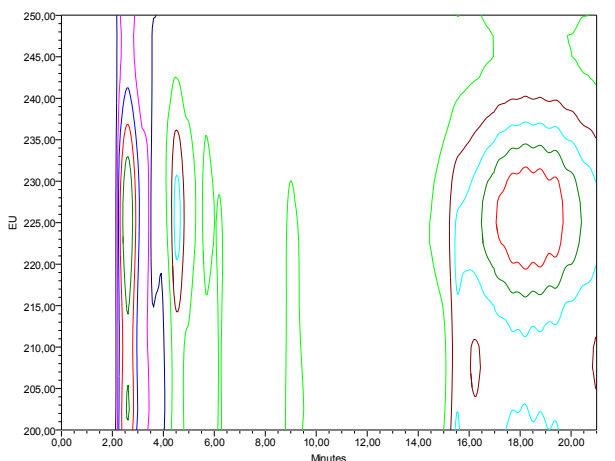

Excitation sweep surfactant 1

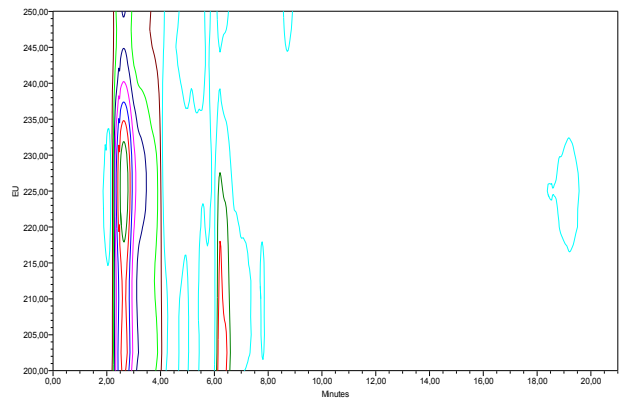

Excitation sweep surfactant 2

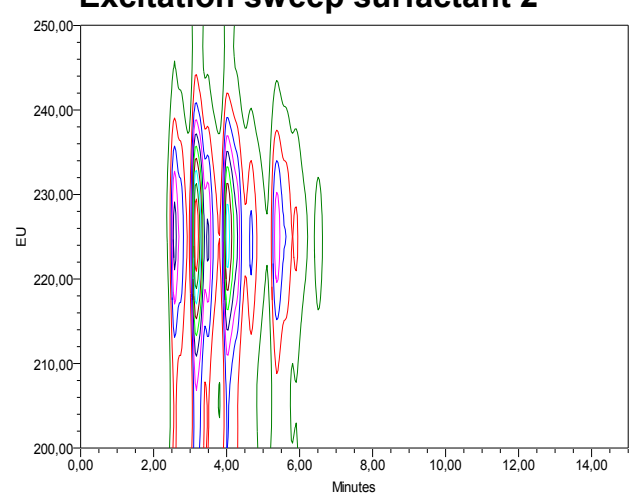

Excitation sweep surfactant 3

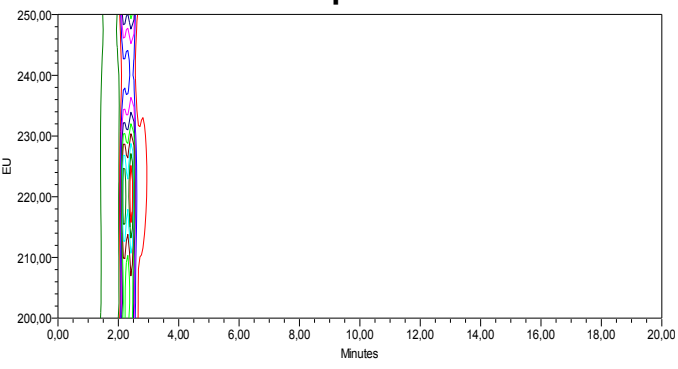

Excitation sweep surfactant 4

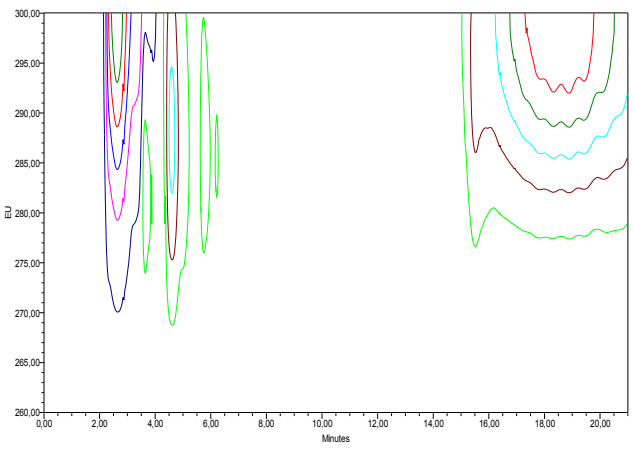

Emission sweep surfactant 1

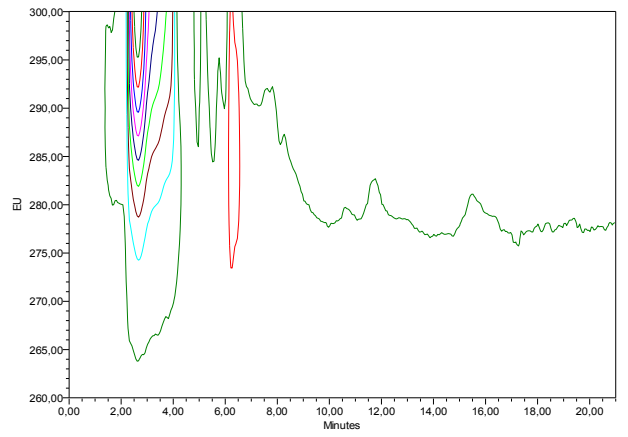

Emission sweep surfactant 2

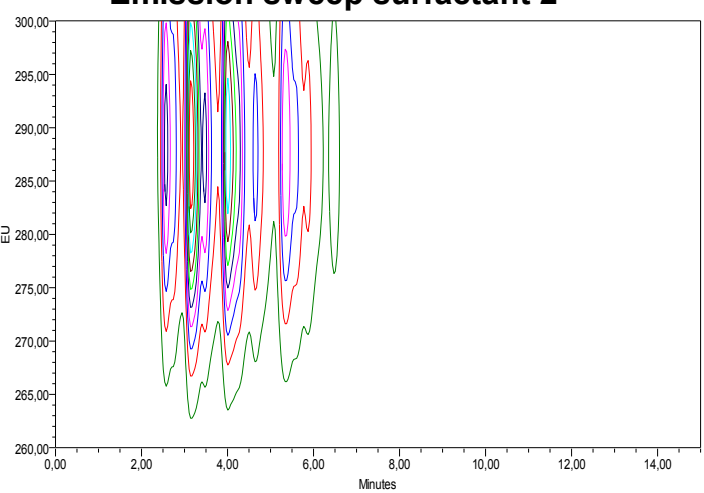

Emission sweep surfactant 3

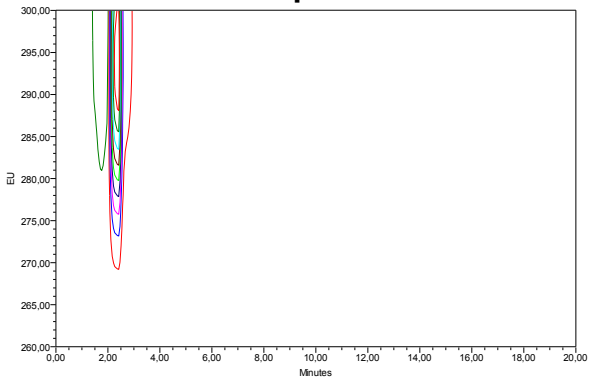

Emission sweep surfactant 4

Fig. 2. Excitation sweep and Emission sweep of the four surfactants tested 


\subsubsection{Standardization}

Pure commercial surfactant compounds are assumed as standards by conveniently diluting them in order to obtain adequate records for their interpretation and calculations.

The tests are started by working with appropriate dilutions so as not to saturate the detector. If the signal was low or zero, the concentration is increased so as to obtain easily observable signals. The range of dilutions used varies according to the injected standard. Thus, the dilutions suitable to work were of the order of $1.10^{-3}$ to $1.10^{-9} \mathrm{v} / \mathrm{v}$, from each pure commercial product.

Taking into account that industrial effluent has solid material in suspension; the technique was adapted using a pre-injection filter to protect the column in future applications.

Blank tests were carried out, injecting distilled water under the same conditions as the standards, in order to check for interfering signals that could appear as a consequence of the pretreatment. It was verified the presence of two characteristic peaks attributable to this operation (2.5 minutes and 3.7 minutes). So they are not taken into account in the interpretation of standards and samples graphs.

\subsubsection{Interferences study}

All tests were performed on the selected working conditions, using commercial detergent for home use as interference for detection of textile surfactans. Signals appeared with retention times that in three cases matched with those of textile use, evidencing the presence of similar constituents (Fig. 2).

From these verifications, information extracted allows comparisons and discriminate the peaks of the surfactants studied. Each component that is own only to one surfactant are highlighted with yellow in Table 1.

Table 1. Retention times of surfactants analyzed

\begin{tabular}{|c|c|c|c|c|c|c|c|c|c|}
\hline \multirow{17}{*}{ 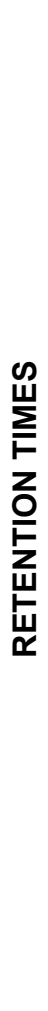 } & & S1 & S2 & S3 & S4 & $C S$ & $D W$ & HPLCW & HPLCWf \\
\hline & 1 & & & & & & & & \\
\hline & 2 & & & & 2 & & & & \\
\hline & & 2,4 & 2,4 & 2,4 & 2,6 & 2,5 & 2,5 & 2,8 & 2,8 \\
\hline & 3 & 3,1 & 3,1 & 2,9 & & & & & \\
\hline & & 3,8 & 3,8 & 3,7 & & 3,8 & 3,7 & & \\
\hline & 4 & & & & & & & & \\
\hline & & & & 4,9 & & & & & \\
\hline & 5 & & & & & & & & \\
\hline & 6 & & & & & & & & \\
\hline & 7 & & & & & & & & \\
\hline & & & & & & & 7,5 & & 7,2 \\
\hline & 8 & & & & & & & & \\
\hline & 9 & & & & & & & & \\
\hline & 10 & & & & & & & & \\
\hline & 11 & & & & & & & & \\
\hline & 12 & 12,2 & & & & & & & \\
\hline
\end{tabular}




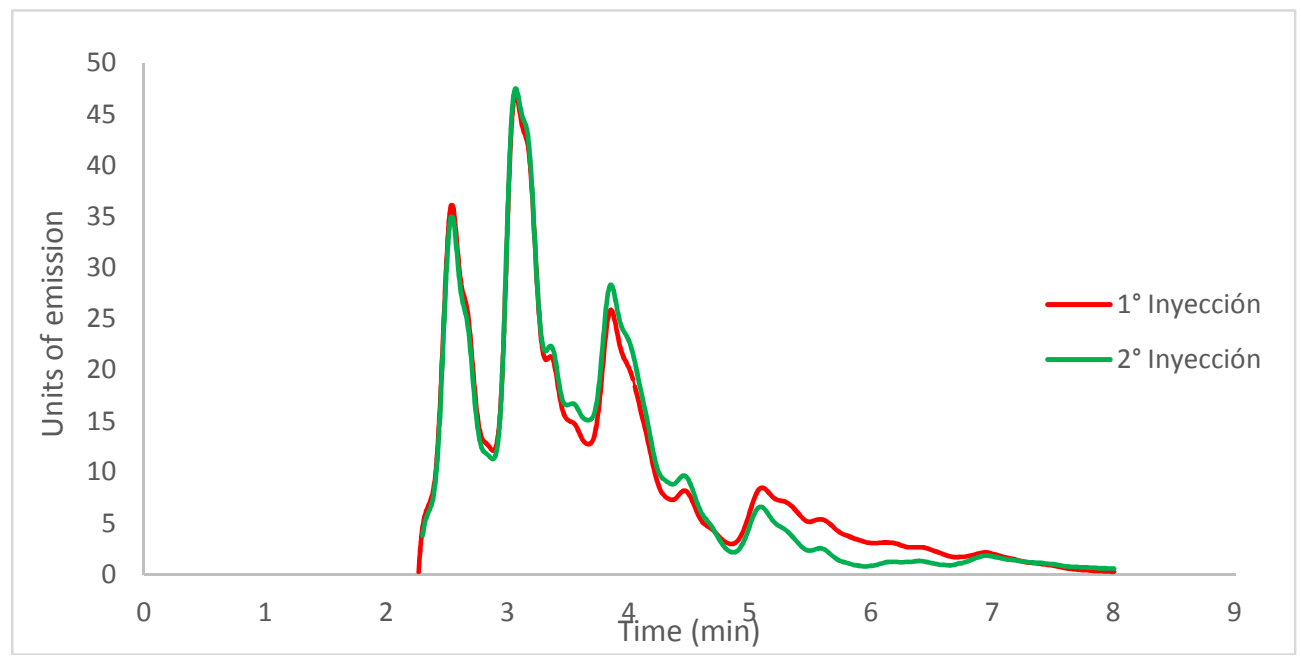

Fig. 3. Chromatogram of detergent for home use

\section{RESULTS AND DISCUSSION}

\subsection{Designed Method}

As a result of this work, it has been possible to develop a technique to determine and quantify surfactant compounds used in textile industry. The final technique by HPLC with fluorescence detector is resumed in Table 2.

Table 2. Surfactants identification and quantification procedure

\begin{tabular}{|c|c|}
\hline Mobile phase: & $\begin{array}{l}\mathrm{H}_{3} \mathrm{CCN} / \mathrm{NaClO}_{4}(12.3 \mathrm{~g} / \mathrm{L}) \\
65: 35\end{array}$ \\
\hline Flow: & $1 \mathrm{~mL} / \mathrm{min}$ \\
\hline Column: & $\begin{array}{l}\text { Waters Symmetry C18 } 5 \\
\mu \mathrm{m} ; 4.6 \times 150 \mathrm{~mm}\end{array}$ \\
\hline Pre-column: & Kromasil 100-5C18 \\
\hline 入ex: & $225 \mathrm{~nm}$ \\
\hline Aem: & $290 \mathrm{~nm}$ \\
\hline
\end{tabular}

With the methodology developed, four surfactants of textile use selected in this work were analyzed to obtain their chromatographic profiles. The profiles show basic information for the subsequent use as reference in terms of the presence and quantities of them in industrial effluents and environmental matrices.

The selected surfactants have in their formulation some common constituents belonging to the same type of compounds with identical fluorescent chemical properties. The chromatographic analysis shows differences and similarities between products of different commercial brands.

\subsection{Chromatograms}

The technique was applied to four surfactants selected, one at a time, at different concentrations, to obtain the calibration curve for each one of the resolved fluorescent compounds. The chromatograms are presented in Figs. 4, 5, 6 and 7.

When performing the screening run, the necessary run time of 15 minutes was decided, because one peak of surfactant 1 was resolved at 12 minutes.

The Chromatogram of surfactant 2 has three peaks, two of them coinciding with the blank test, and one with the retention times of surfactants 1 and 3 .

The Chromatogram of surfactant 3 has four peaks, two of them coinciding with the blank test and a peak $\mathrm{TR}=4.9$ minutes which is characteristic of surfactant 3 .

The Chromatogram of surfactant 4 presents only two peaks, coinciding one of them with one of the times of retention of the blank test, so it has only one characteristic peak for this product, TR $=2$ minutes.

Different retention times are shown in Table 1, proving different types of fluorescent constituents in the surfactants tested. It is further evidence that several of them are the same according to their retention time obtained in the individual chromatograms. Fig. 8 shows overlapping chromatograms of all surfactants tested in this work, evidencing the write before. 


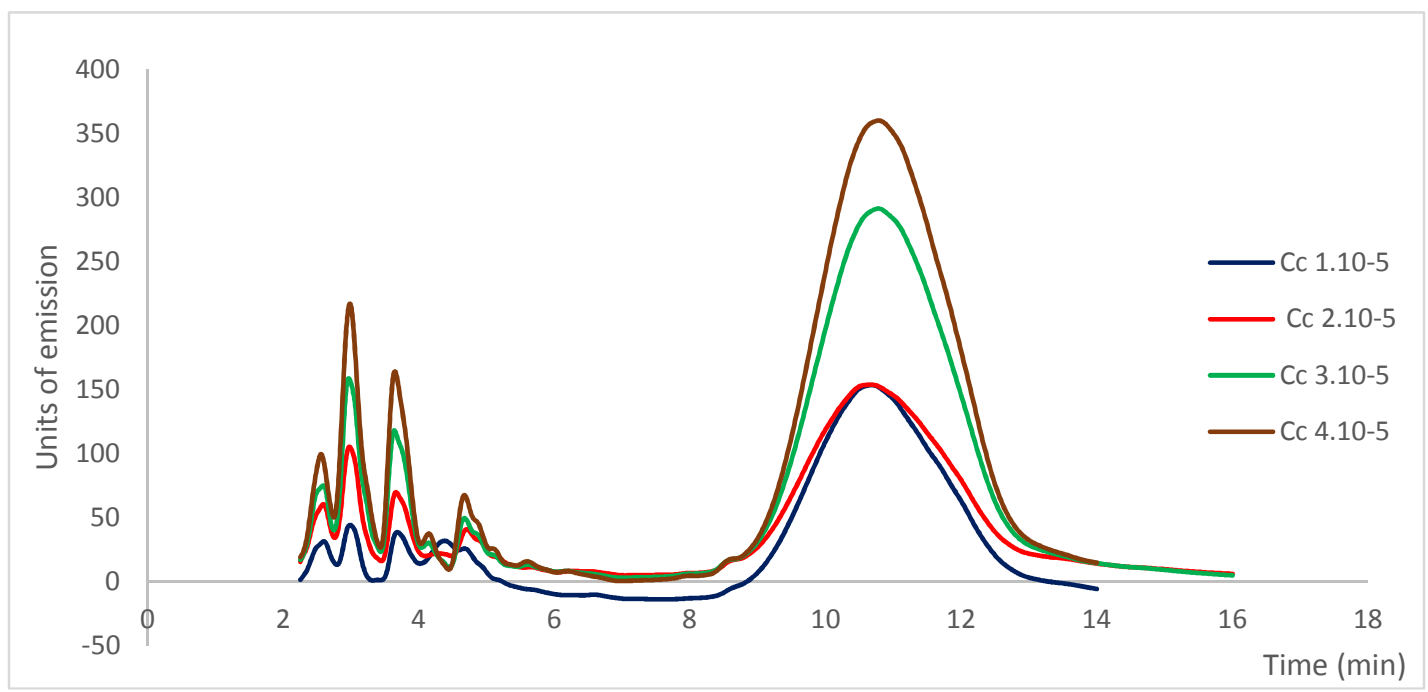

Fig. 4. Chromatograms of Surfactant 1

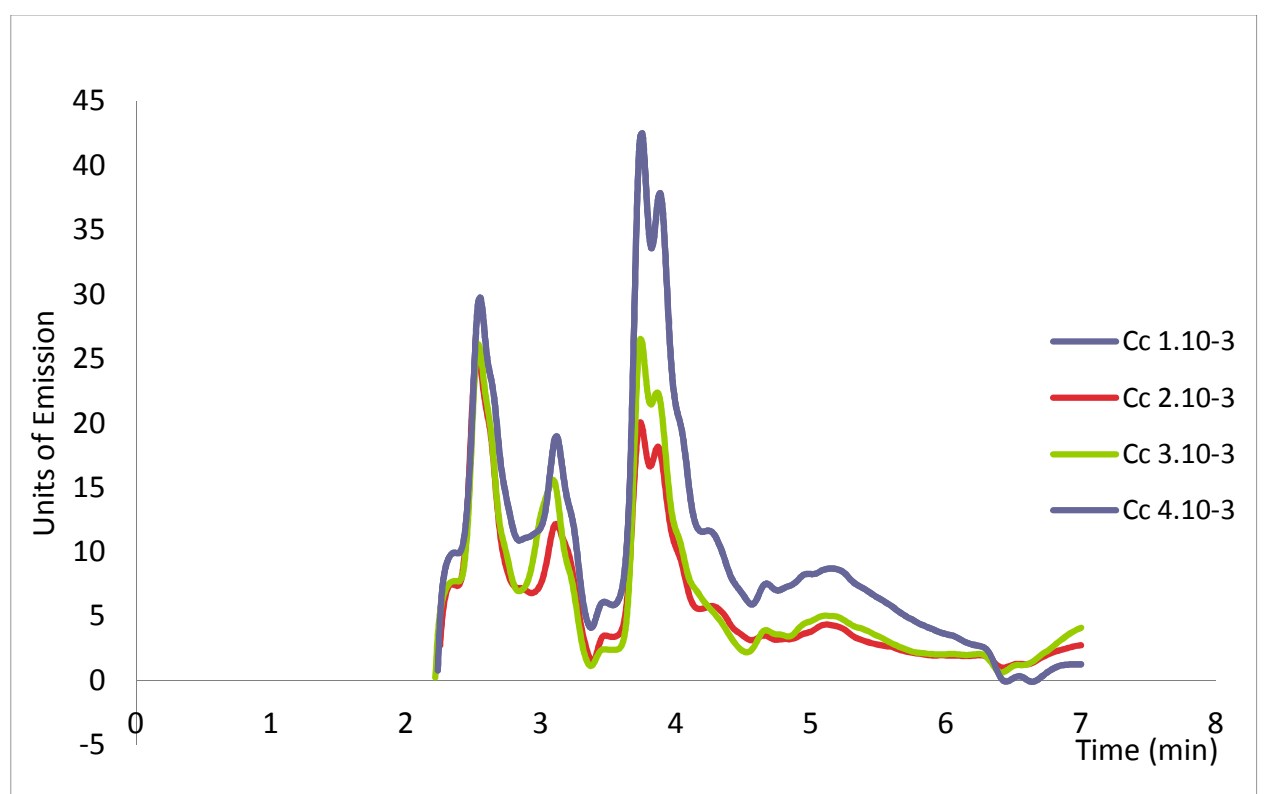

Fig. 5. Chromatograms of Surfactant 2

Table 3. Comparison of parameters of different surfactants analyzed

\begin{tabular}{llll}
\hline & Surfactant 1 & Surfactant 3 & Surfactant 4 \\
\hline Retention time & $12.2 \mathrm{~min}$ & $4.9 \min$ & $2.0 \mathrm{~min}$ \\
Analytical Sensitivity & $1.38 \cdot 10^{9}$ & $5.81 .10^{8}$ & $2.04 .10^{9}$ \\
$\operatorname{LOD}(\mathrm{g} / \mathrm{L})$ & $2.39 \cdot 10^{-5}$ & $4.47 \cdot 10^{-5}$ & $1.98 .10^{-6}$ \\
$\mathrm{LOQ}(\mathrm{g} / \mathrm{L})$ & $6.60 \cdot 10^{-5}$ & $1.23 \cdot 10^{-4}$ & $5.46 .10^{-6}$ \\
\hline
\end{tabular}

\subsection{Calibration Curves. Figures of Merit}

This test was performed to qualify the developed methodology to be able to compare its analytical properties with other similar techniques and thus obtain information about its reliability. All tests were done using MATLAB (Mathworks Inc., Natick, MA, USA). For the own peaks of every surfactant tested, the univariate statistical 
analysis and its figures of merit are presented in Table 3.

Since surfactant 2 does not exhibit any fluorescent compound which characterizes it, statistical analysis was not performed.

All other surfactants analyzed have their homoscedastic calibration data: the graphs of residues (not showed) present constant variances and their distribution are random. Moreover, it was verified that all satisfy the linearity test.
LOQ found by Motteran et al. [9] was $300 \mu \mathrm{g} / \mathrm{L}$ for LAS and LAE, while in the present work it was found a LOQ of 66.0, 123 and $54.6 \mu \mathrm{g} / \mathrm{L}$ for Surfactant 1,3 and 4 respectively. It was an advantage, in one hand because the lower LOQ, and in another hand because the method propose in the present research is more affordable. In another papers, Castles et al. [8] and Loos et al. [13] found lower LOQ than it was found in the present work, but they use a preconcentration before applied his method.

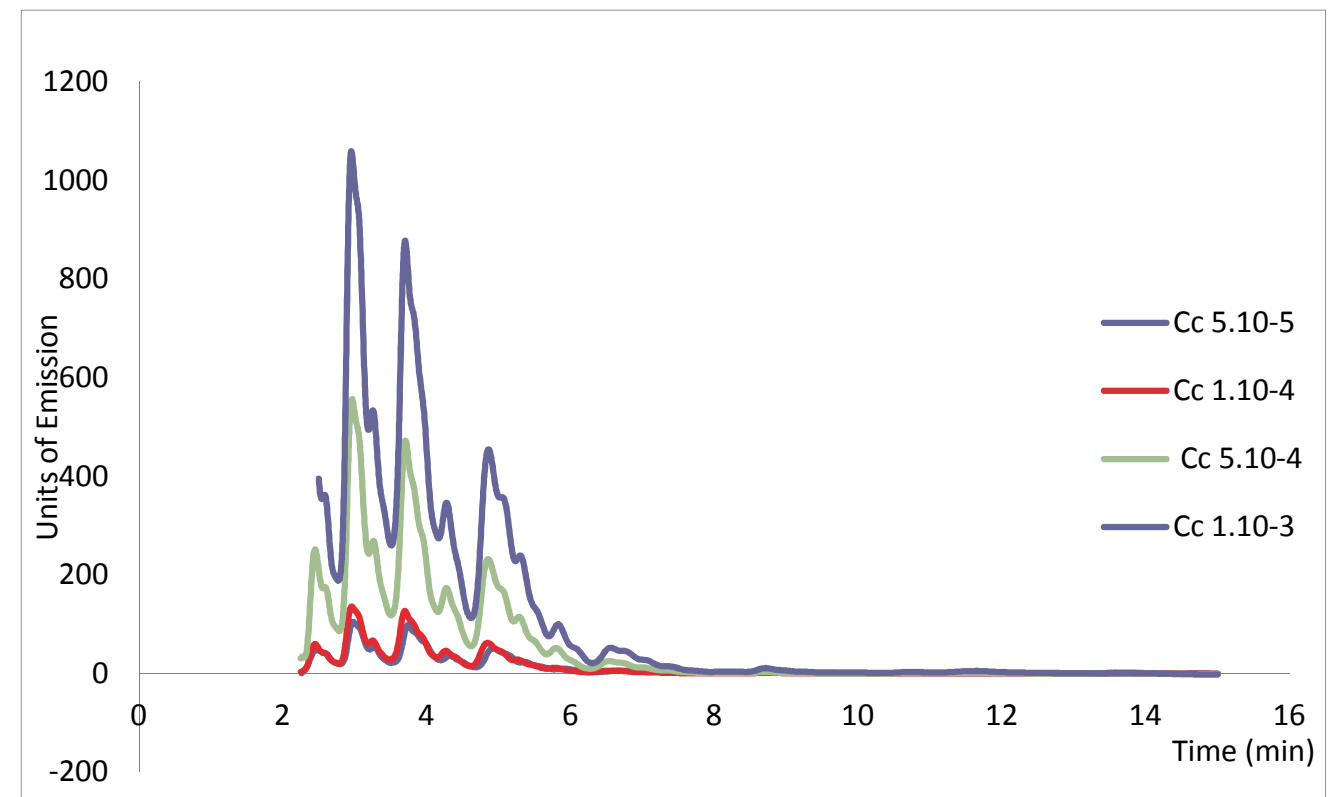

Fig. 6. Chromatograms of Surfactant 3

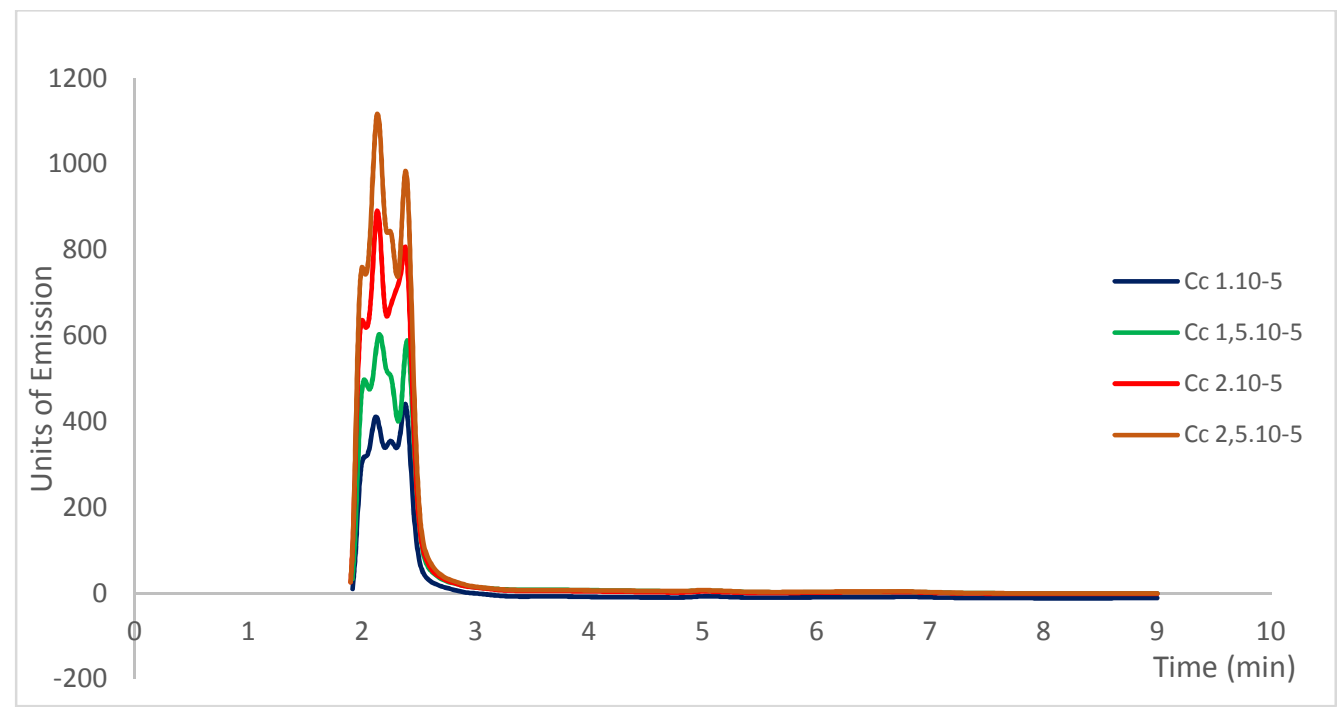

Fig. 7. Chromatograms of Surfactant 4 


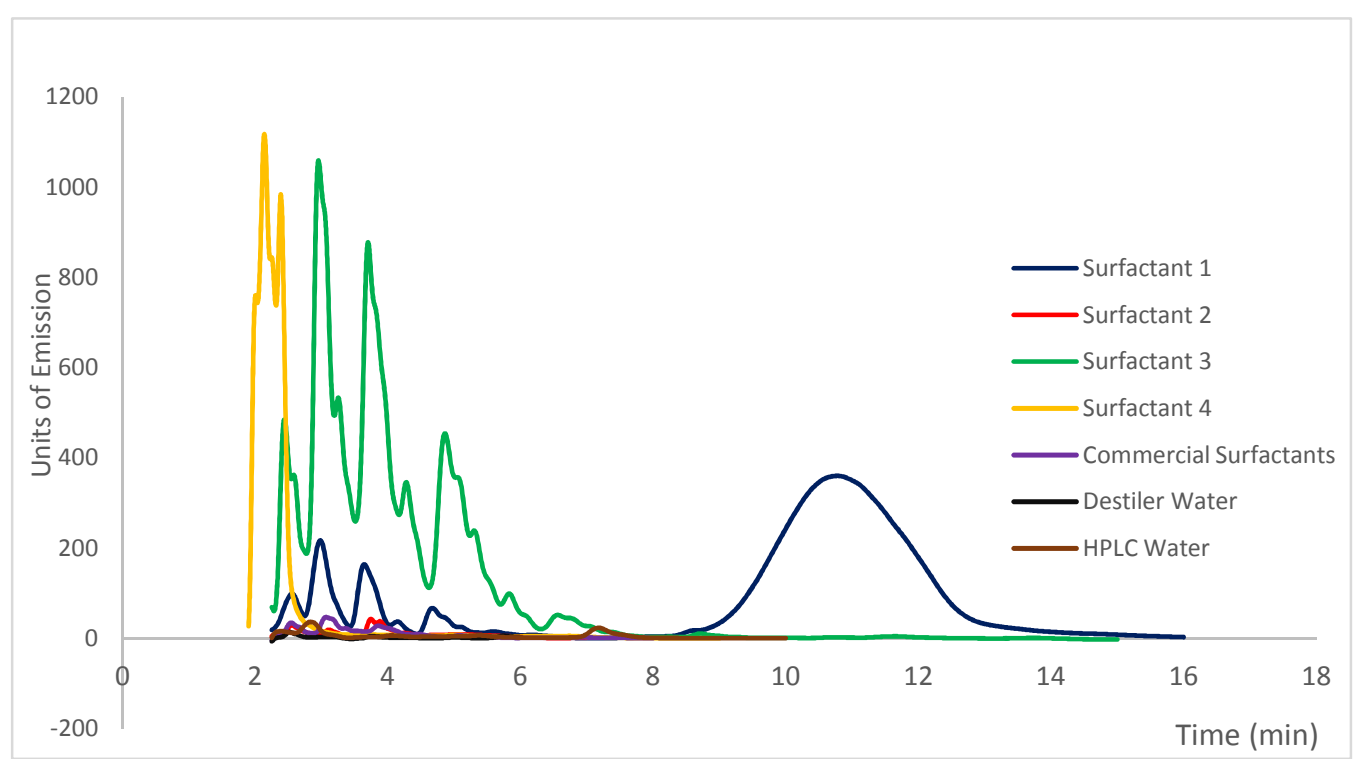

Fig. 8. Chromatograms of all superimposed surfactants

\section{CONCLUSION}

The analytical methodology designed by HPLCFluorescence is feasible and reliable, for the detection and quantification of fluorescent compounds present in commercial surfactant that are used in textile industries for their manufacturing process.

It was verified that commercial surfactants of common industrial use have constituents that coincide but the surfactants analyzed have their own characteristics that identify and discriminate them. The Surfactants 1, 3 and 4 have their own fluorescent compounds, which will be used as indicators of contamination for the monitoring or evaluation of the environmental impact of textile effluents to water bodies.

\section{ACKNOWLEDGEMENTS}

The authors would like to thank the Secretaría General de Ciencia y Técnica de la Universidad Nacional del Nordeste (PI 004/2014) for financially supporting this work.

The authors also would like to thank the Laboratorio de Química Ambiental and its Director Juan Daniel Ruiz Díaz for providing the laboratory where the determinations were made.

\section{COMPETING INTERESTS}

Authors have declared that no competing interests exist.

\section{REFERENCES}

1. Hemachandra $\mathrm{CK}$, Pathiratne A. Combination of physico-chemical analysis, Allium cepa test system and Oreochromis niloticus erythrocyte based comet assay/nuclear abnormalities tests for cytogenotoxicity assessments of treated effluents discharged from textile industries. Ecotoxicology and Environmental Safety. 2016;131:54-64.

2. Nawaz MS, Ahsan M. Comparison of physico-chemical, advanced oxidation and biological techniques for the textile wastewater treatment. Alexandria Eng J. 2014;53(3):717-722.

3. Kravets L. Biodegradation of nonionic surfactants used by the textile industry. Technical Bulletin Shell Chemical Company; 1982.

4. Nishikawa $M$, Katagi $M$, Miki $A$, Tsuchihashi $\mathrm{H}$. Determination of surfactant by liquid chromatography / electrospray ionization mass spectrometry and liquid chromatography / electrospray ionization tandem mass spectrometry. Forensic Toxicological. 2003;49(2):138-148.

5. Hirayama $\mathrm{Y}$, Ohmichi $M$, Tatsumoto $\mathrm{H}$. Simple and rapid determination of golf course pesticides by in-tube solid-phase microextraction coupled with liquid chromatography. J Heal Sci. 2005;51(5): 526-532. 
6. Kamaya M, Sugimoto H, Yamaguchi Y. A Simple and Rapid Method for the Detection of Non-Ionic Surfactants. 2014;(5):11211128.

7. Hong J, Slingsby R. Automated solidphase extraction of linear alkylbenzene sulfonate in wastewater using a Weak Anion-Exchange Cartridge Followed by HPLC with UV Detection. 2013;2-4.

8. Castles MA, Moore BL, Ward SR. Measurement of Linear Alkylbenzenesulfonates in Aqueous Environmental Matrices by Liquid Chromatography with Fluorescence Detection. Anal. Chem. 1989;2534-2540.

9. Motteran F, Lima Gomes PCF, Silva EL, Varesche MBA. Simultaneous determination of anionic and nonionic surfactants in commercial laundry wastewater and anaerobic fluidized bed reactor effluent by online column-switching liquid chromatography/tandem mass spectrometry. Sci Total Environ.
10. Reemtsma T. Methods of analysis of polar aromatic sulfonates from aquatic environments. J Chromatogr A. 1996; 733(1-2):473-489.

11. Hirayama $\mathrm{Y}$, Ohmichi $\mathrm{M}$, Tatsumoto $\mathrm{H}$. Simple and rapid determination of golf course pesticides by in-tube solid-phase microextraction coupled with liquid chromatography. J Heal Sci. 2005;51(5): 526-532.

12. Castles MA, Moore BL, Ward SR. Measurement of linear alkylbenzenesulfonates in aqueous environmental matrices by liquid chromatography with fluorescence detection. Anal Chem. 1989;61(22):2534-2540.

13. Loos R, Hanke G, Umlauf G, Eisenreich SJ. LC-MS-MS analysis and occurrence of octyl- and nonylphenol, their ethoxylates and their carboxylates in Belgian and Italian textile industry, waste water treatment plant effluents and surface waters. Chemosphere. 2007;66(4):690699.

(c) 2017 Martínez et al.; This is an Open Access article distributed under the terms of the Creative Commons Attribution License (http://creativecommons.org/licenses/by/4.0), which permits unrestricted use, distribution, and reproduction in any medium, provided the original work is properly cited.

Peer-review history:

The peer review history for this paper can be accessed here: http://sciencedomain.org/review-history/21205 